DOI: $10.15593 / 2224-9354 / 2018.4 .24$

УДК 332.122:001.895

\author{
Ю.С. Балянова, М.Б. Макарова, И.Г. Севастьянова \\ ТЕНДЕНЦИИ РАЗВИТИЯ ИННОВАЦИОННОГО \\ СЕКТОРА ПЕРМСКОГО КРАЯ
}

\begin{abstract}
Одним из основных условий перехода от экспортно-сырьевой к инновационной модели экономического роста является развитие региональной инновационной системы. Главная цель эффективного функционирования инновационной системы региона состоит в активизации имеющегося научно-технического потенциала. Для выработки стратегических решений и основополагающей линии действий в соответствии с поставленной целью необходим мониторинг сильных и слабых сторон региональной инновационной системы. В статье представлены результаты анализа динамики инновационного развития Пермского края за 2012-2016 годы в рейтинге традиционно сложившихся конкурентов, к которым относятся Свердловская область, Республики Татарстан и Башкортостан. Отмечен незначительный рост коэффициента обновления основных фондов в крае при высокой доле инвестиций, направленных на реконструкцию и модернизацию. Дана оценка эффективности использования передовых технологий в крае. Показано, что за исследуемый период наблюдается спад инновационной деятельности в Пермском крае и регионахконкурентах. На основе государственных статистических данных по основным показателям научно-технической деятельности края выявлена низкая творческая активность изобретателей. Сделан вывод о том, что для обеспечения устойчивого экономического роста и повышения региональной конкурентоспособности необходима опора на высокотехнологичные и наукоемкие отрасли, накопленный научно-технологический потенциал и высококвалифицированные кадры.

Ключевые слова: динамика инновационного развития, регионы-конкуренты.
\end{abstract}

Одним из важных инструментов государственного управления инновационным развитием регионов являются региональные инновационные системы (РИС) [1-5]. Эффективное управление инновационными процессами на уровне региона требует знания сильных и слабых сторон РИС для выработки стратегических решений и основополагающей линии действий в соответствии с поставленными целями и решаемыми задачами $[6,7]$.

В этой связи представляется актуальным проведение анализа складывающейся ситуации в инновационном секторе Пермского края. В рамках данного исследования проанализированы отдельные показатели РИС, на-

() Балянова Ю.С., Макарова М.Б., Севастьянова И.Г., 2018

Балянова Юлия Сергеевна - магистрант кафедры микропроцессорных средств автоматизации ФГБОУ ВО «Пермский национальный исследовательский политехнический университет», e-mail: yuliya.balyanova@mail.ru.

Макарова Мария Борисовна - магистрант кафедры микропроцессорных средств автоматизации ФГБОУ ВО «Пермский национальный исследовательский политехнический университет», e-mail: mariiamakarova79@gmail.com.

Севастьянова Ираида Геннадьевна - д-р техн. наук, профессор кафедры микропроцессорных средств автоматизации ФГБОУ ВО «Пермский национальный исследовательский политехнический университет», e-mail: mariborisovna-mk@yandex.ru. 
глядно характеризующие динамику инновационного развития Пермского края и традиционно сложившихся его конкурентов.

Оценка экономической эффективности инновационной деятельности Пермского края за последние 5 лет показала, что при высокой доле инвестиций, направленных на реконструкцию и модернизацию (рис. 1), среди регионов-конкурентов край демонстрирует незначительный рост (4 \%) коэффициента обновления основных фондов (табл. 1) [8-11].

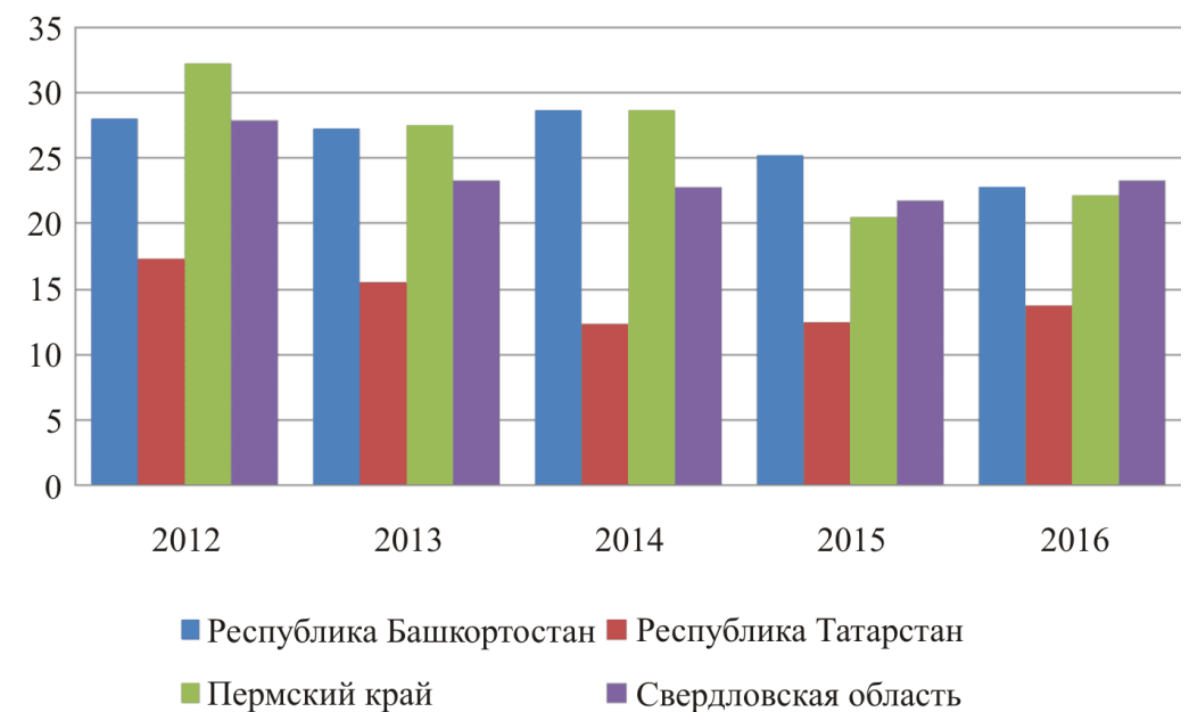

Рис. 1. Доля инвестиций, направленных на реконструкцию и модернизацию, в общем объеме инвестиций в основной капитал регионов за 2012-2016 годы, \%

Таблица 1

Коэффициент обновления основных фондов регионов за 2012-2016 годы, \%

\begin{tabular}{|l|c|c|c|c|c|}
\hline \multicolumn{1}{|c|}{ Регион } & 2012 & 2013 & 2014 & 2015 & 2016 \\
\hline Пермский край & 7,3 & 7,6 & 7,9 & 8,1 & 8,3 \\
\hline Республика Татарстан & 9,8 & 11,8 & 11,9 & 12,8 & 10,3 \\
\hline Республика Башкортостан & 8,4 & 9,4 & 9,1 & 8,9 & 9,8 \\
\hline Свердловская область & 7,4 & 7,1 & 7,7 & 6,2 & 9,4 \\
\hline
\end{tabular}

Особое место в концепции развития инновационного сектора края занимает проблема стимулирования импорта технологий, научно-технических знаний и экспорта собственных технологий и наукоемкой продукции. Так, за исследуемый период по количеству разработанных передовых производственных технологий Пермский край занимает 3-е место между Свердловской областью и Республикой Татарстан (рис. 2), а по количеству используемых передовых технологий находится на последнем месте среди своих конкурентов (табл. 2). 


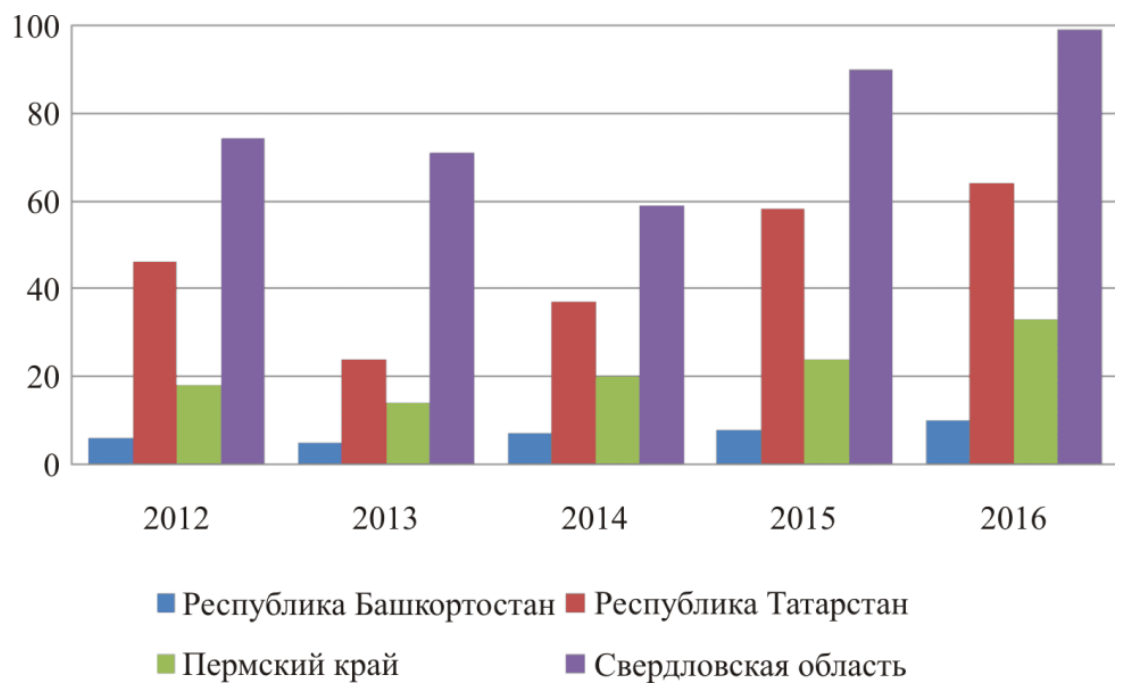

Рис. 2. Разработанные передовые производственные технологии регионов за 2012-2016 годы, ед.

Таблица 2

Используемые передовые производственные технологии регионов за 2012-2016 годы, ед.

\begin{tabular}{|l|c|c|c|c|c|}
\hline \multicolumn{1}{|c|}{ Регион } & 2012 & 2013 & 2014 & 2015 & 2016 \\
\hline Пермский край & 4392 & 4395 & 4596 & 4764 & 4815 \\
\hline Республика Татарстан & 5151 & 5280 & 6025 & 6675 & 7355 \\
\hline Республика Башкортостан & 6372 & 6612 & 7192 & 7625 & 9324 \\
\hline Свердловская область & 10704 & 9595 & 9050 & 9697 & 10379 \\
\hline
\end{tabular}

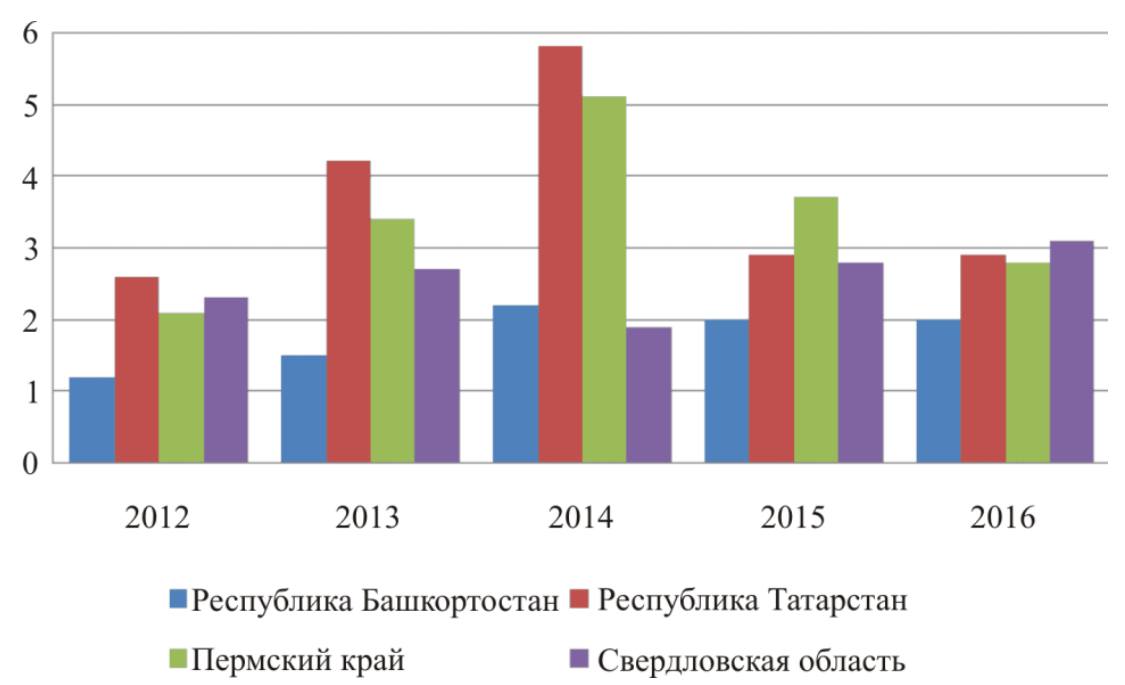

Рис. 3. Удельный вес затрат на технологические инновации регионов за 2012-2016 годы, \% 
В целом по рассматриваемым регионам Приволжского федерального округа за исследуемый период наблюдается спад инновационной деятельности, о чем свидетельствует снижение удельного веса затрат на технологические инновации (рис. 3) и инновационной активности организаций (табл. 3) [8].

Таблица 3

Инновационная активность организаций регионов за 2012-2016 годы, \%

\begin{tabular}{|l|c|c|c|c|c|}
\hline \multicolumn{1}{|c|}{ Регион } & 2012 & 2013 & 2014 & 2015 & 2016 \\
\hline Пермский край & 14,1 & 10,9 & 11,6 & 10,5 & 7,9 \\
\hline Республика Татарстан & 19,1 & 21,2 & 20,5 & 20,5 & 21,3 \\
\hline Республика Башкортостан & 12,8 & 12,3 & 10,4 & 9,1 & 7,3 \\
\hline Свердловская область & 13,6 & 11,5 & 11,7 & 8,3 & 9,4 \\
\hline
\end{tabular}

Среди регионов-конкурентов за 2012-2016 годы. Пермский край находится на последнем месте по патентной деятельности (табл. 4).

Таблица 4

Патентная деятельность регионов за 2012-2016 годы

\begin{tabular}{|l|c|c|c|c|c|}
\hline \multicolumn{1}{|c|}{ Регион } & 2012 & 2013 & 2014 & 2015 & 2016 \\
\hline Пермский край & $393 / 393 *$ & $400 / 348$ & $385 / 317$ & $360 / 366$ & $399 / 252$ \\
\hline Республика Башкортостан & $585 / 566$ & $668 / 492$ & $718 / 481$ & $662 / 737$ & $692 / 486$ \\
\hline Республика Татарстан & $961 / 722$ & $789 / 705$ & $864 / 781$ & $808 / 882$ & $723 / 632$ \\
\hline Свердловская область & $568 / 493$ & $556 / 475$ & $539 / 455$ & $526 / 509$ & $551 / 411$ \\
\hline
\end{tabular}

* Подано патентных заявок, ед. / выдано патентов, ед.

Одной из основных проблем, требующих активного регионального поведения, является конкурентоспособность не только материального, но и интеллектуального производства, ориентированного на высокие и устойчивые темпы роста [12-14]. Подтверждением того, что для решения этой проблемы требуется разработка и внедрение эффективного механизма власти и управления на местах под запросы новой экономики, может служить следующая статистическая информация (табл. 5) [15].

Таблица 5

Динамика изменения уровня основных показателей научно-технического потенциала Пермского края за 2012-2016 годы

\begin{tabular}{|l|c|c|c|c|c|}
\hline \multicolumn{1}{|c|}{ Показатель } & 2012 & 2013 & 2014 & 2015 & 2016 \\
\hline $\begin{array}{l}\text { Численность персонала, занятого научными } \\
\text { исследованиями и разработками, чел. }\end{array}$ & 10034 & 10319 & 10588 & 11005 & 10304 \\
\hline $\begin{array}{l}\text { Организации, выполняющие научные } \\
\text { исследования и разработки, ед. }\end{array}$ & 60 & 59 & 59 & 71 & 68 \\
\hline Поступление патентных заявок, ед. & 626 & 664 & 560 & 491 & 542 \\
\hline Выдано патентов, ед. & 586 & 556 & 536 & 486 & 356 \\
\hline
\end{tabular}


При росте численности персонала, занятого научными исследованиями и разработками, наблюдается низкая творческая активность изобретателей края. За период 2012-2014 годов выдано лишь 5 патентов на 100 специалистов, а за последние два года количество выданных патентов на 100 специалистов снизилось до 3 ед.

Реализация намеченных программ по развитию инновационного сектора региона напрямую связана с промышленной политикой, базирующейся на таких направлениях, как разработка и выпуск наукоемкой продукции, использование новых управленческих, финансовых и производственных технологий, создание современной структуры региональных рынков сбыта. Важно понимать, что основной целью региональной инновационной политики сегодня является не только создание благоприятных правовых, организационных и экономических условий в интересах обеспечения устойчивого социально-экономического развития, а также распределение функций и ролей технической и социальной подсистем. Максимальное использование мер регулирования инновационной сферы, опирающихся на выбор отраслевых приоритетов, позволит сформировать сопряженные высокопроизводительные технологические цепочки и обеспечить в перспективе появление мультипликативных эффектов. Кроме того, для обеспечения развития региона по сценарию импортозамещающей инустриализации нужен пересмотр базовых организационных принципов в форме структур, функций и людей. При выборе конкретных целей региональной политики целесообразна ориентация на критерии соответствия выбранных приоритетов специфическим требованиям субъекта с учетом ресурсного потенциала.

В этой связи все большее значение для регионов приобретает развитие основных хозяйственно-технологических «точек роста», стратегическая ориентация на которые дает возможность определить позиции промышленных предприятий за доступ к отечественным и зарубежным рынкам сбыта. У Пермского края имеется существенный задел в ряде отраслей по решению задачи реконструкции региональной экономики. Генераторами новых технических и технологических решений в крае являются высокотехнологичные и наукоемкие компании, входящие в ведущие корпоративные промышленно-производственные кластеры ракетного двигателестроения «Технополис “Новый Звездный”» и волоконно-оптических технологий «Фотоника» (рис. 4). Они имеют мощную базу для проведения научно-исследовательских и опытно-конструкторских работ и активно участвуют в реализации долгосрочных научно-технических программ и проектов для приоритетных направлений науки, технологий и техники.

Эффективность принципа «кластерности» заключается в том, что его участники, обслуживая разные отраслевые сегменты, не конкурируют между собой. Благодаря своему потенциалу по широкой номенклатуре разрабатываемой и производимой продукции, в частности в области насосно-компрессорного обо- 
рудования и энергетического машиностроения, предприятия региональных кластеров имеют возможность внести значительный вклад в реализацию государственного плана по импорто-замещению в ряде ведущих отраслей России.
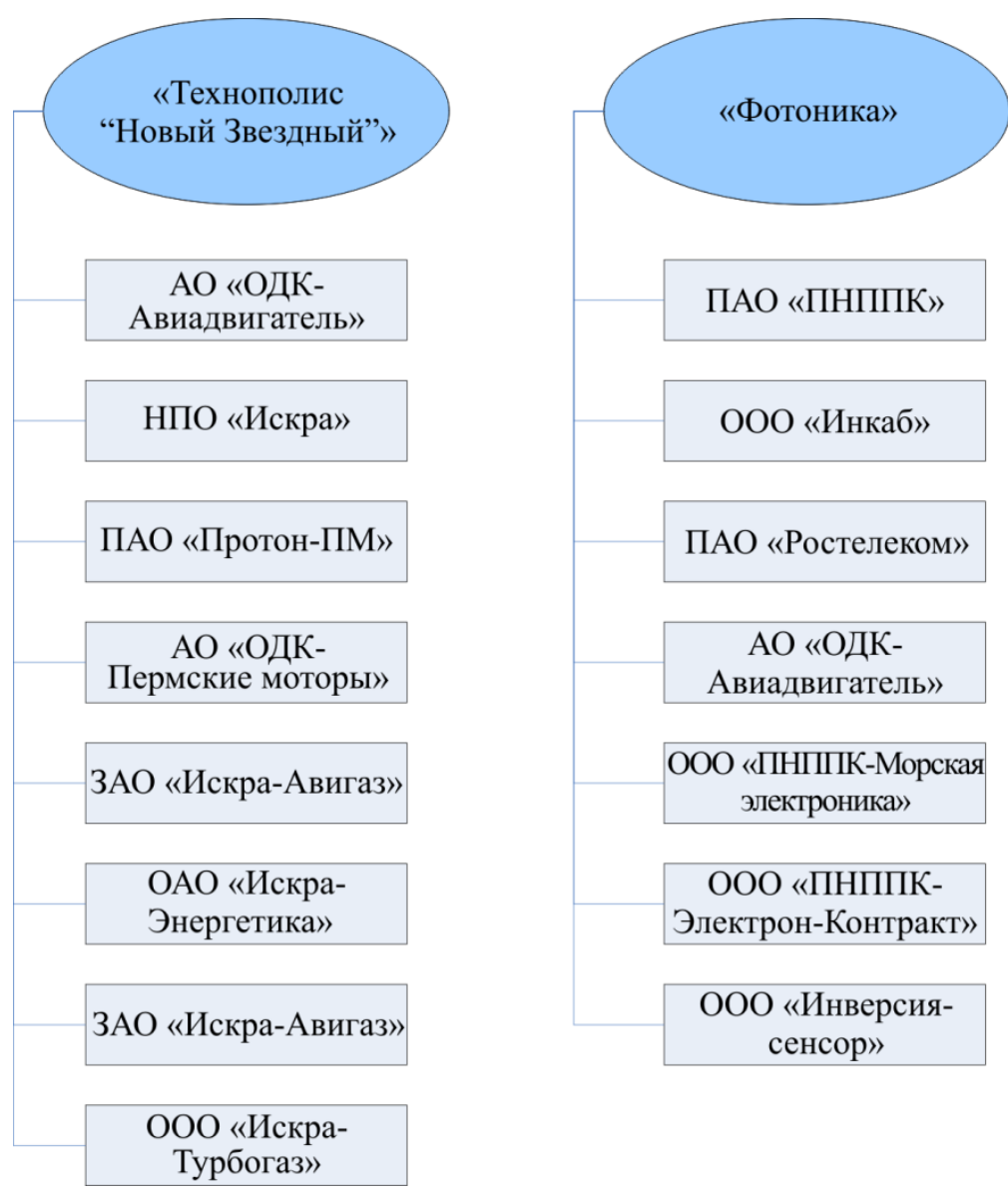

Рис. 4. Якорные участники кластеров Пермского края

Таким образом, инновационный тип развития края требует ориентации на региональную специфику и концентрации усилий на эффективном использовании научно-технического и интеллектуального капитала. В разработке стратегии повышения региональной конкурентоспособности целесообразна опора на высокотехнологичные и наукоемкие отрасли, накопленный научно-технический потенциал и высококвалифицированные кадры. Для этого необходимо наличие четких приоритетов развития региона и активных действий по их реализации [16-18]. При этом особую роль должны сыграть механизмы эффективной капитализации интеллектуального капитала, развития промышленных производств, проектных организаций, предпринимательского сектора с высокой добавленной стоимостью для обеспечения устойчивого экономического роста $[19,20]$. 
У Пермского края имеется значительный ресурс промышленного производства. Устойчивая структура и большой удельный вес профилирующих отраслей специализации, включающих нефтегазовую промышленность, энергетическое машиностроение и станкостроение, является важной предпосылкой формирования нового сценария включения региона в новую экономическую кооперацию страны.

\section{Список литературы}

1. Воротников А. Конкурентоспособность регионов и задачи региональных властей в области корпоративной политики // Всероссийский экономический журнал. - 2001. - № 7. - С. 94-97.

2. Горюнова Л.А. Управление инновационной системой региона. Инструменты и механизмы управления: моногр. - СПб.: Изд-во СПбГУЭФ, 2001. -216 с.

3. Мухамедьяров А.М., Диваева Э.А. Региональная инновационная система: развитие, функционирование, оценка, эффективность. - Уфа: АН РБ, Гилем, 2010. - 188 с.

4. Стратегия инновационного развития Российской Федерации на период до 2020 года [Электронный ресурс]: утв. Распоряжением Правительства РФ от 08.12.2011 № 2227-p. - URL: http://government.ru/docs/9282/ (дата обращения: 3.02.2018).

5. Суханова П.А. Модель региональной инновационной системы: отечественные и зарубежные подходы к изучению региональных инновационных систем // Вестник Пермского университета. Экономика. - 2015. - № 4(27). C. $92-102$.

6. Гончаренко Л.П., Арутюнов Ю.А. Инновационная политика: учеб. М.: КНОРУС, 2014. $-350 \mathrm{c}$.

7. Инновационный менеджмент: многоуровневые концепции, стратегии и механизмы инновационного развития: учеб. пособие / под ред. В.М. Аньшина, А.А. Дагаева.- М.: Дело, 2013. - 584 с.

8. Территориальный орган Федеральной службы государственной статистики по Пермскому краю [Электронный ресурс]. - URL: http://permstat.gks.ru/ wps/wcm/connect/rosstat_ts/permstat/ru/ (дата обращения: 6.02.2018).

9. Территориальный орган Федеральной службы государственной статистики по Свердловской области [Электронный pecypc]. - URL: http://sverdl.gks.ru/wps/wcm/connect/rosstat_ts/sverdl/ru/ (дата обращения: 12.02.2018).

10. Территориальный орган Федеральной службы государственной статистики по Республике Башкортостан [Электронный ресурc]. - URL: http://bashstat.gks.ru/wps/wcm/connect/rosstat_ts/bashstat/ru/ (дата обращения: 19.02.2018).

11. Территориальный орган Федеральной службы государственной статистики по Республике Татарстан [Электронный ресурс]. - URL: http:/tatstat.gks.ru/ wps/wcm/connect/rosstat_ts/tatstat/ru/ (дата обращения: 26.02.2018). 
12. Бухвальд Е.М. Инновационное развитие регионов: роль децентрализации полномочий // Пространственная экономика. - 2013. - № 1. - С. 55-68.

13. Штерцер Т.А. Детерминанты инновационной активности на региональном рынке // Вестник НГУ. Социально-экономические науки. - 2005. Т. 5, вып. 2. - С. 100-110.

14. Смирнов В.В. К вопросу об организации эффективного управления развитием региона // Региональная экономика: теория и практика. - 2013. № 4. - С. $48-57$.

15. Федеральная служба государственной статистики [Электронный реcypc]. - URL: http://www.gks.ru/wps/wcm/connect/rosstat_main/rosstat/ru/ (дата обращения: 20.03.2018).

16. Севастьянова И.Г., Докшина М.А. О механизмах поддержки инновационной деятельности в условиях модернизации российской экономики // Фундаментальные исследования. - 2016. - № 2-1 - С. 202-205.

17. Письмак В.Н. Новые формы организации инновационного процесса // Экономист. - 2003. - № 9. - С. 53-55.

18. Завлин Н.Н. Стимулирование инновационной деятельности // Инновации. - 2000. - № 7(8). - С. 64-65.

19. Каменских М.А., Постников В.П. Повышение конкурентоспособности региона на основе организации инновационной структуры // Региональная экономика: теория и практика. - 2013. - № 2 (281). - С. 39-44.

20. Кандалинцев В.Г. Инновационный бизнес: применение сбалансированной системы показателей. - М.: Дело, 2014. - 168 с.

\section{References}

1. Vorotnikov A. Konkurentosposobnost' regionov i zadachi regional'nykh vlastei v oblasti korporativnoi politiki [The Competitiveness of the regions and the tasks of regional authorities in the field of corporate policy]. Vserossiiskii ekonomicheskii zhurnal, 2001, no. 7, pp. 94-97.

2. Goriunova L.A. Upravlenie innovatsionnoi sistemoi regiona. Instrumenty i mekhanizmy upravleniia [Management of innovative system of the region. Instruments and control mechanisms], St. Petersburg, St. Petersburg State University of Economics and Finance, 2001, 216 p.

3. Mukhamed'iarov A.M., Divaeva E.A. Regional'naia innovatsionnaia sistema: razvitie, funktsionirovanie, otsenka, effektivnost [Regional innovation systems: Development, operation, evaluation, effectiveness]. Ufa, AN RB, Gilem, 2010, 188 p.

4. Strategiia innovatsionnogo razvitiia Rossiiskoi Federatsii na period do 2020 goda [Strategy of innovative development of the Russian Federation for the period up to 2020]. RF Government Regulation of 08.12.2011 no. 2227-p, available at: http://government.ru/docs/9282/ (accessed 03 February 2018). 
5. Sukhanova P.A. Model' regional'noi innovatsionnoi sistemy: otechestvennye i zarubezhnye podkhody k izucheniiu regional'nykh innovatsionnykh sistem [The model of a regional innovation system: national and foreign approaches]. Vestnik Permskogo universiteta. Ekonomika, 2015, no. 4(27), pp. 92-102.

6. Goncharenko L.P., Arutiunov Iu.A. Innovatsionnaia politika [Innovation policy]. Moscow, KNORUS, 2014, $350 \mathrm{p}$.

7. Innovatsionnyi menedzhment: mnogourovnevye kontseptsii, strategii i mekhanizmy innovatsionnogo razvitiia [Innovative management: Multilevel concepts, strategies and mechanisms of innovative development]. Ed. V.M. An'shin, A.A. Dagaev. Moscow, Delo, 2013, 584 p.

8. Territorial'nyi organ Federal'noi sluzhby gosudarstvennoi statistiki po Permskomu kraiu [Territorial body of the Federal state statistics service for Perm Krai], available at: http://permstat.gks.ru/ wps/wcm/connect/rosstat_ts/permstat/ru/ (accessed 06 February 2018).

9. Territorial'nyi organ Federal'noi sluzhby gosudarstvennoi statistiki po Sverdlovskoi oblasti [Territorial body of the Federal state statistics service of the Sverdlovsk region], available at: http://sve-rdl.gks.ru/wps/wcm/connect/rosstat_ts/ sverdl/ru/ (accessed 12 February 2018).

10. Territorial'nyi organ Federal'noi sluzhby gosudarstvennoi statistiki po Respublike Bashkortostan [Territorial body of the Federal state statistics service of the Republic of Bashkortostan], available at: http://bash-stat.gks.ru/wps/wcm/connect/ rosstat_ts/bashstat/ru/ (accessed 19 February 2018).

11. Territorial'nyi organ Federal'noi sluzhby gosudarstvennoi statistiki po Respublike Tatarstan [Territorial body of the Federal state statistics service of the Republic of Tatarstan], available at: http://tatstat.gks.ru/wps/wcm/connect/rosstat_ ts/tatstat/ru/ (accessed 26 February 2018).

12. Bukhval'd E.M. Innovatsionnoe razvitie regionov: rol' detsentralizatsii polnomochii [Innovative development of regions: the role of decentralization of power]. Prostranstvennaia ekonomika, 2013, no. 1, pp. 55-68.

13. Shtertser T.A. Determinanty innovatsionnoi aktivnosti na regional'nom rynke [Determinants of innovation activity in the regional market]. Vestnik NGU. Sotsial'no-ekonomicheskie nauki, 2005, vol. 5, no. 2, pp. 100-110.

14. Smirnov V.V. K voprosu ob organizatsii effektivnogo upravleniia razvitiem regiona [On the organization of effective management of regional development]. Regional'naia ekonomika: teoriia i praktika, 2013, no. 4, pp. 48-57.

15. Federal'naia sluzhba gosudarstvennoi statistiki [Federal state statistics service], available at: http://www.gks.ru/wps/wcm/connect/rosstat_main/rosstat/ru/ (accessed 20 March 2018).

16. Sevast'ianova I.G., Dokshina M.A. O mekhanizmakh podderzhki innovatsionnoi deiatel'nosti $\mathrm{v}$ usloviiakh modernizatsii rossiiskoi ekonomiki [About mechanisms of innovation activity support in conditions of Russian economy modernization]. Fundamental'nye issledovaniia, 2016, no. 2-1, pp. 202-205. 
17. Pis'mak V.N. Novye formy organizatsii innovatsionnogo protsessa [New forms of organization of the innovation process]. Ekonomist, 2003, no. 9, pp. 53-55.

18. Zavlin N.N. Stimulirovanie innovatsionnoi deiatel'nosti [Promotion of innovation]. Innovatsii, 2000, no. 7(8), pp. 64-65.

19. Kamenskikh M.A., Postnikov V.P. Povyshenie konkurentosposobnosti regiona na osnove organizatsii innovatsionnoi struktury [Improving the competitiveness of the region on the basis of the organization of innovative structure]. Regional'naia ekonomika: teoriia i praktika, 2013, no. 2(281), pp. 39-44.

20. Kandalintsev V.G. Innovatsionnyi biznes: primenenie sbalansirovannoi sistemy pokazatelei [Innovative business: The use of the balanced scorecard]. Moscow, Delo, 2014, 168 p.

Оригинальность $75 \%$

Получено 25.04.2018 Принято 27.05.2018 Опубликовано 28.12.2018

Yu.S. Balyanova, M.B. Makarova, I.G. Sevastyanova

\title{
TENDENCIES OF DEVELOPMENT OF INNOVATIVE SECTOR OF THE PERM KRAI
}

\begin{abstract}
One of the main conditions for the transiting from a raw material model of economic growth to an innovative one is development of a regional innovation system. The main goal of effective functioning of the latter is to enhance the available scientific and technical potential. To develop strategic decisions and a fundamental line of action in accordance with the stated goal, it is necessary to monitor the strengths and weaknesses of the regional innovation system. The article presents the results of the analysis of the dynamics of innovative development of the Perm Krai for 2012-2016 in the rating of long-established competitors which include the Sverdlovsk Region, the Republics of Tatarstan and Bashkortostan. A slight increase in the coefficient of renewal of fixed assets in the Perm krai was observed along with a high share of investments into reconstruction and modernization. The estimation of efficiency of using advanced technologies in the Perm krai is given. The analyzed period saw a decline in innovation activity in the Perm Krai and in the competitor regions. Based on the state statistics on the main indicators of scientific and technical activities of the region, the creative activity of inventors was rated as low. It is concluded that to ensure sustainable economic growth and increase regional competitiveness, it is necessary to rely on high-tech and knowledge-intensive industries, accumulated scientific and technological potential and highly qualified personnel.
\end{abstract}

Keywords: dynamics of innovative development, competitor regions.

Yuliya S. Balyanova - Master's Student, Department of Microprocessor-Based Automation, Perm National Research Polytechnic University, e-mail: yuliya.balyanova@mail.ru.

Mariya B. Makarova - Master's Student, Department of Microprocessor-Based Automation, Perm National Research Polytechnic University, e-mail: mariiamakarova79@gmail.com.

Iraida G. Sevastyanova - Doctor of Engineering, Professor, Department of Microprocessor-Based Automation, Perm National Research Polytechnic University, e-mail: mariborisovna-mk@yandex.ru.

Received 25.04.2018 Accepted 27.05.2018 Published 28.12.2018 